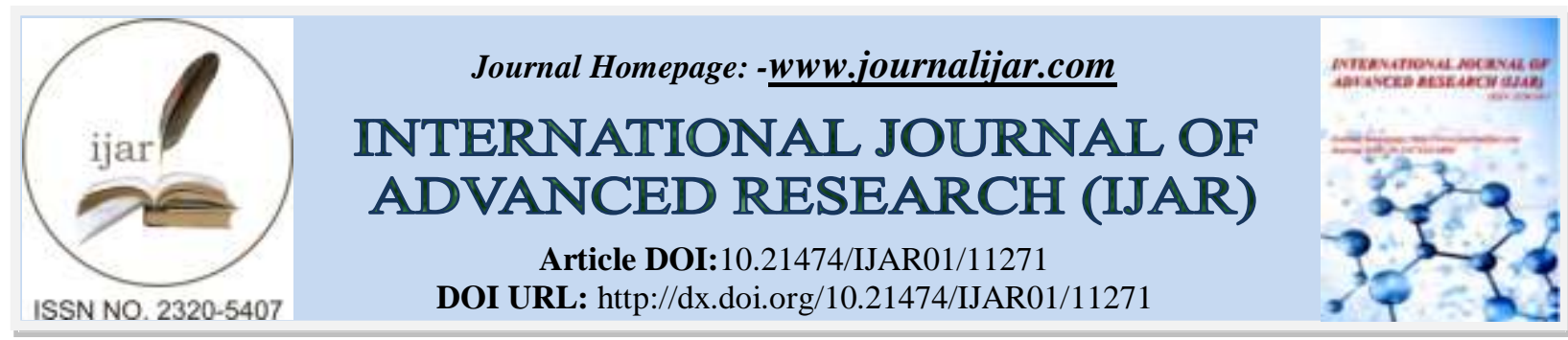

RESEARCH ARTICLE

\title{
RADIO FOR ROHINGYA REFUGEES: ASSESSING THE IMPORTANCE AND EFFECTIVENESS AS COMMUNICATION TOOLS
}

\author{
Dilshad Hossain Dodul ${ }^{1}$, Zakaria Khan ${ }^{2}$ and MD Ashraful Goni ${ }^{3}$ \\ 1. Assistant Professor, Department of Journalism and Media Studies, Stamford University Bangladesh. \\ 2. Assistant Professor, Department of Mass Communication and Journalism, Jagannath University \\ 3. Lecturer, Department of Mass Communication and Journalism, Bangladesh University of Professional (BUP).
}

\section{Manuscript Info}

Manuscript History

Received: 05 May 2020

Final Accepted: 10 June 2020

Published: July 2020

Key words:-

Radio, Humanitarian Communication, Rohingya, Aid and Security

\begin{abstract}
Bangladesh is home for more than 800,000 Rohingya Refugees and this is the most densely crowded refugee camps around the world. Since 2017 The Government, along with humanitarian organizations, is implementing humanitarian aid projects to the Rohingya people but till now communicating with the Rohingya people is one of the biggest obstacles for them. Researchers of this study will explore the importance of Radio to provide necessary information for refugees regarding aid and security issues and its contribution to fulfilling the demand for the entertainment of refugees. To understand how important radio as a communication tool is, researchers of this study have followed the concept of humanitarian communication and have conducted a survey among refugees and a Focus Group Discussion with opinion leaders of refugee camps and the findings from the survey and FGD leads them to believe that as a communication tool, Radio can play a very effective role and lessen crisis of Rohingya refugees.
\end{abstract}

Copy Right, IJAR, 2020,. All rights reserved.

\section{Introduction:-}

The world has seen a massive refugee influx into Bangladesh while a large number of Rohingya people, living in Rakhine state in Myanmar, fled to neighbouring Coxs Bazar, one of the south-eastern districts of Bangladesh, in August 2017, after a massive army crackdown held on Rohingya community leaving hundreds of them dead, injured or raped. Since then more than 710,000 have crossed the Myanmar-Bangladesh border to reach the largest refugee camps in the world situated in Teknaf and Ukhia of Coxs Bazaar. As per the latest update of UNHCR, 860,243 Rohingya refugees are living in 187,534 households inside the camps (UNHCR 2020). As per the OCHA (United Nations Office for the Coordination of Humanitarian Affairs), 'The vast majority live in 34 extremely congested camps, including the largest single-site, the Kutupalong-Balukhali Expansion Site, which is host to approximately 626,500 Rohingya refugees'(OCHA 2017).

Bangladesh government along with local and international humanitarian organisations are trying their best to provide aids and information about aid inside the camp and applying different types of communication strategies to do so. As the world has been experiencing different refugee crisis since the last decade, it is evident that proper Information is as important and can be considered as aid as the other basic needs for refugees. Humanitarian organisations are mostly applying interpersonal and public communication tools to provide aid and security related information to Rohingya refugee camps in Bangladesh and the objective of this research is to unfold how Radio is 
playing a very effective tool of communication for Rohingya refugees. As some of the recent researches showed rapid emergence of digital technology is opening new ways of providing humanitarian aid to refugees, however researchers of this study believe, considering the socio-cultural situation of Rohingya refugees, radio still has a lot to offer while it comes to effective communication with Rohingya people. (Backhaus 2019) describes the importance of radio to refugees saying Community radio offers a social technology that embodies a 'hybrid' approach to diffusion and participation. Drawing on ethnographic research conducted at a rural community radio station in South India, this article argues that community radio facilitates the sharing of technical information and innovations among farmers and contributes to amplifying existing knowledge communication systems.

Health response is a very important part of humanitarian aid for refugees as (Hugelius, Adams, and Romo-Murphy 2019)said 'Access to reliable information in a language that is easily understood and culturally appropriate is part of the Core Humanitarian Standard. Establishing communication and access to reliable information can facilitate health recovery and reduce mortality after disasters. From a historical perspective, public radio has been used worldwide as a communication method in emergencies and disaster situations, mainly for communication on disaster preparedness, risk awareness or risk reduction.'

Humanitarian organisations especially German radio Deutsche Welle (DW), Bangladesh Betar (Government-owned Radio) and BBC Media action are making audio content for Rohingya refugees using their language and most of the contents are about giving information and increasing awareness about health issues. This study will explore different aspects of using Radio as a communication tool with three Research questions given below.

\section{Research Question:}

1. If the radio is an effective communication tool for Rohingya refugees?

2. What is the importance of radio for Rohingya people as a medium of entertainment?

3. How do the uses of radio for refugees go with the concept of humanitarian communication?

\section{Study Design:}

This study followed a mixed-method approach to understand the impact of radio on the Rohingya population. Researchers apply a survey method to collect the quantitative data and Focus group discussion (FGD) for qualitative data in a Rohingya camp named D-25. 15 survey questionnaires were asked among 50 respondents based on random sampling to prove the unbiased representation of the population(Hansen and Machin 2018). Researchers have collected the individual respondent's data with intensive care. Though it was a survey, researchers have collected the data following the process of a semi-structured interview. They spend extra time with every respondent to make this survey as accurate as possible.

FGD method used for analysing the impact of radio on the Rohingyas life and to recognize their perspective on the radio as a communication tool(O. Nyumba et al. 2018). The focused group discussion was conducted with a group of 30 people. In FGD Rohingya leaders known as "Majhi", Imam and other opinion leaders were interviewed for focus group discussion to explore the impact of radio. The age group of the respondents for focus group discussion ranged from 30 - 60 years.

To analyze the survey data researcher has have constructed a coding schedule with different variables. Variables such as age, gender, radio preference, marital status, family members, belief, information sharing capacity and dependency have been added in the coding schedule to monitor and analyze the data. Researchers have collected the data according to the coding schedule. Survey data was coded by hand and then later it was typed into a computer data analysis programme (Microsoft Excel). Statistical analysis Package for the Social Sciences (SPSS) is used to analyze the survey data.

\section{Theoretical Framework:}

Using ICTs to tackle the crisis, natural or manmade, have been very popular among responding organisations because it has opened several effective ways of communicating message more easily and rapidly among the affected population during the crisis. However, this increasing rate of using ICTs among humanitarian workers yet to make radio, a proven tool for effective communication during any types of crisis, less important, especially when it comes to spreading information among a large number of people living in a specific place like refugee camps. Organisations, working to provide humanitarian aid are preferred to define the pattern of communication they do with the crisis-affected people as 'Humanitarian communication which popularly thought as the 'humanitarian use of 
ICTs'. But (Raymond, Card, and al Achkar 2015)written an article title 'What is humanitarian communication' for European Interagency Security Forum where they proposed three criteria which should be present in communication activities to be defined as humanitarian communication. These criteria, in short, known as Three 'P's, Populations, principles and purposes. The population are referred for both, crisis-affected people and organisations working for them, who are communicating with each other and using ICTs to communicate. Principles are about four basic principles by NGO code of conduct; 7, humanity, impartiality, neutrality, and independence and Purpose is about communication to save lives and dignity.

Some researchers emphasised the importance of establishing a feedback mechanism as it creates a two-way flow of information between humanitarian actors and affected communities. According to IOM (2014), Feedback mechanisms enable expectancy supervision and serve as a yardstick for communities to hold the humanitarian community accountable. (Wilson, Moses and Wilson, 2019).

International Organization for Migration (IOM) has conceptualized the model of humanitarian communication and consider two components which are required in humanitarian communication which include "Taking into account the information needs of and feedback from affected communities in developing an appropriate information response; and Providing communications service to humanitarian actors by disseminating assistance-related information to affected communities"(Wilson, Moses, and Wilson 2019). In an article titled 'Principles and Practice of Humanitarian Communication during and After Natural Disasters and Armed Conflicts', researchers described three types of humanitarian communication, operational, Beneficiary and communication for development. Operational communication is about the exchange of information between humanitarian workers and interlocutors, who usually are government officials, academics or people from civil society organizations. Beneficiary communication encourages people living in a crisis to participate in two-way communication and give feedback after getting necessary information and communication for development (C4D) also encourage enhanced participation and "promote social change using the methods and instruments of interpersonal communication, community media and modern information technologies. The aim is to enhance community engagement, social mobilization and behaviour change"(Wilson et al. 2019). Radio, as a communication tool, cover beneficiary communication and communication for development and thus, as a researcher of this study believes, it is a tool for humanitarian communication in Rohingya refugee camps in Bangladesh.

\section{Literature Review:-}

(Hugelius et al. 2019) analyzed studies and reports from 13 papers, covering the use or impact of humanitarian radio in several large-scale natural disasters. They have covered the practical use of radio, physical health promotion, psychosocial health promotion and the promotion of community resilience. The study finds that humanitarian radio has been used to provide health-related information, advice and psychosocial support in the event of natural disasters, thereby contributing to the health and well-being of affected populations from a physical, psychosocial and community perspective. Radio has the potential to reach large populations in severely damaged areas and could, therefore, be a useful and powerful health response to natural disasters. As such, health professionals; crisis management specialists, e.g. broadcast journalists; and emergency managers should be prepared to use humanitarian broadcast as part of their response to natural disasters. They also stated that radio has been used in the immediate response to many forms of natural disasters and to relay news, information or advice to impacted areas with a variety of parties concerned.

Zaatari Radio is an ambitious humanitarian project that serves a culture that has been ravaged by war in Zaatari, Jordan. This radio station allows war-affected people to confront the challenges facing them as refugees in the region. The project aimed to broadcast health campaigns, disseminate practical information such as services for refugees and provide a community hub for local musicians(Macaulay 2016).

On the occasion of world radio day (UNHCR 2020) stated that, in addition to providing emergency shelter and relief to displaced Iraqis, UNHCR has partnered with media organizations to provide them with a credible source of news and information. The initiative is supported by BBC Media Action and Radio Nawa, a public radio service broadcast in Arabic and Kurdistan. Transmitters have been installed in camps and UNHCR and its partners have been distributing radio kits to families, enabling them to receive broadcasts, participate in conversations and make informed decisions about their future. 
(Butler 2018) in his news article mentioned about a community radio in Paris called Stalingrad connection. This radio station aims to help refugees living in France. This radio offers them a mix of news and information for asylum-seekers in several languages including Arabic and English.

(Kristina and Polykastro 2016) tells the story of no border radio, a radio station in a makeshift camp in Greece. A guitar-like Kurdish instrument, Syrian Seban Rashid plays live on the radio as a singer takes a microphone and joins him while others line up on their phones with their chosen songs to order. The idea for the radio station came from demonstrators who started one at Gezi Park in Istanbul during the 2013 protests. "No Border Radio" broadcasts interviews and music in Arabic, Kurdish, and English by refugees and host the regular shows in Italian as well. She added that refugees seeking asylum say the information is one of the things they want most. A radio station in a fortune-telling camp in Greece aims to give them that along with a voice to the world.

(Mesmar et al. 2016) argued that, digital technology has the potential to play a role in facilitating humanitarian action and improving health determinants. Rigorous evaluation of emerging technology in humanitarian crises must be incorporated into design and implementation to strengthen the basis of evidence for decision-making, including its health effects. Findings highlight the fact that digital technologies enable the collaboration, coordination and collection and review of large volumes of data, allowing for timely responses in humanitarian contexts, sudden disasters.

(Hansrod 2018) tells the story of radio Naf, how this small radio station for the Teknaf fishing community, has developed into a broadcaster/information vector for a country deeply impacted by humanitarian catastrophe. Radio $\mathrm{Naf}$ is a Bangladeshi community radio station that began to focus on the needs of Rohingya refugees in August 2017, following the large influx of people fleeing genocide in Myanmar into southeastern Bangladesh. She also added that the different camps in Cox's Bazaar do not all catch a radio reception, so Radio Naf has set up 22 listener clubs where the programs are broadcast to a mixed group of 20 men, women, young people and elderly people who are instructed to share the information with people in their homes and neighbourhoods.

(Jasmin and Andrea 2020) explain how Radio Naf produces informative reports from a rickshaw, called a "Miking" in the time of the global pandemic. They have stated that the mike is mounted on a motor rickshaw that passes through the Rohingya camp and loudly plays a traditional song about the novel coronavirus with lyrics. The people in the refugee camp and the surrounding villages have difficulty accessing information via other communication channels. The volunteers in the camps had held interviews for their radio reports before the outbreak of the pandemic.

This point is clear that radio played an important role in the humanitarian crisis in every corner of the world even in Rohingya Refugee camp, but the question remains if the radio is still powerful in the era of social media or why radio is still a useful tool for humanitarian crisis communication.

\section{Findings and Data Analysis}

This study will analyse the data in two phases:

1. Findings from the survey

2. Findings from focus group discussion (FGD)

\section{Findings from Survey: \\ Listening Radio is popular among people above mid-twenties:}

People above 25 tended to listen to radio more than refugees under the age of 25 . As researchers found male refugees, who are comparatively young usually busy working with different NGO projects or trying to start a business on their own inside the camps whereas female refugees who are under 25 are mostly busy to give care to their children as most of the women of that age group have little kids. Refugees, male or female, from the age group of 26 to 35 dominate the socio-political decision taken collectively by Rohingya refugees. For instance, many of the Majhis (camp leaders) belong to that age group and maintain communication with government and non-government officials and play an important role in decision making for the camps they are monitoring. Senior members, especially females, who are above 45, also found radio a good source of information regarding health issues and depend on this medium. Researchers found three respondents who are passive listeners which means they seek information from those who regularly listen to the radio but not listen directly because radio is not available to them. Researcher keeps them as respondents to understand how radio influence its passive listeners. 
Table 1:- Age group and State of radio listening.

\begin{tabular}{|l|l|l|l|}
\hline Age group * State of radio listening Crosstabulation & \multirow{2}{*}{ Total } \\
\cline { 1 - 3 } Age group & State of radio listening & \\
\cline { 2 - 4 } & Yes & No & 11 \\
\hline $18-25$ years & 11 & 0 & 18 \\
\hline $26-35$ years & 18 & 0 & 9 \\
\hline $36-45$ years & 7 & 2 & 12 \\
\hline $45+$ years & 11 & 1 & 50 \\
\hline Total & 47 & 3 & \\
\hline
\end{tabular}

News is more preferred than entertainment content:

Crisis affected people require information as much as their basic needs such as food, water, shelter or medicine. For them, information is another kind of aid which can save their lives and resources. Getting information through radio get the most priority for Rohingya refugees for a certain reason. Camps are situated in an area which was previously a forest and all the basic services have been installed in 2017 and often temporary. Every little change of those services, from getting food bags from WHO offices to Getting legal aid from Camp in Charge offices, can make a big change in their lives. That is why information, which they often mention as News is the most important radio content for them as $83 \%$ of respondents said that they prefer listening news over entertainment. A big portion of the population inside camps are children and a large number of women are pregnant. Thus, news about maternal and child health care is the most listened content among female respondents. Domestic violence against women is also very common inside camps and thus news about legal aid from CIC offices are also getting priority among female respondents. Male respondents are mostly into political and international news relevant to them. Some of the respondents said they do not listen to entertainment content because listening to music or drama is not allowed in Islam which indicates that religious belief of Rohingya refugees also refrains some of them to listen entertainment content.

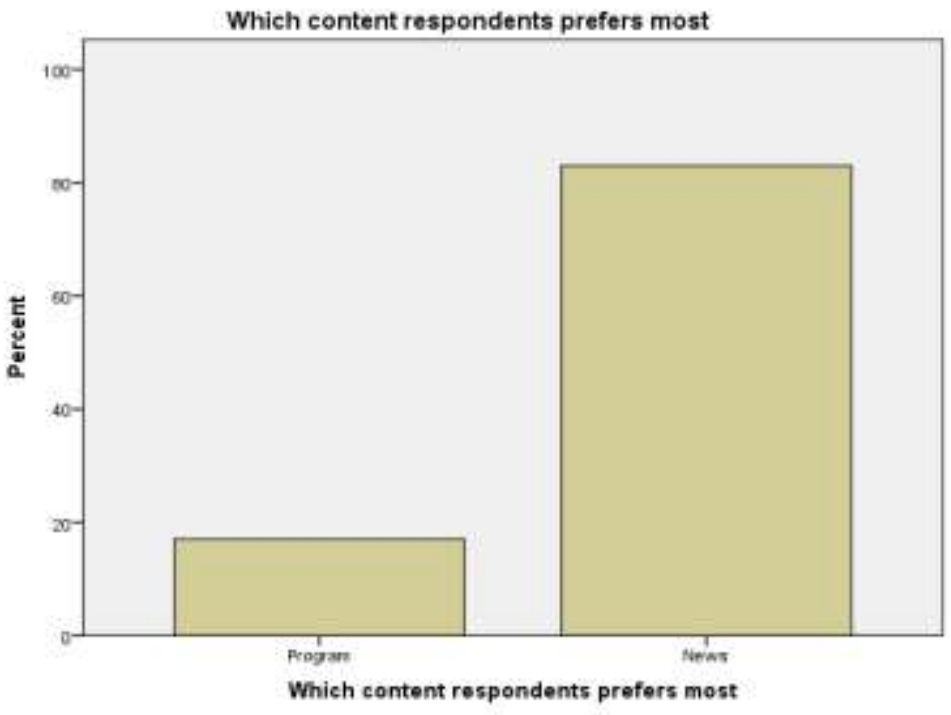

Chart 1:- Content preference.

The community Radio channel is more popular than the national one:

Radio Naf, which is popular among $62 \%$ of respondents, produce news and entertainment in Rohingya language. They involve representatives from the Rohingya community to make contents in the local language. Making easily communicable programs for refugees and taking their representative in those programs are the two reasons behind the popularity of Radio Naf. FM Channels from Myanmar, which some ties accessible from Camps, is the source of entertainment for Rohingya people because radio channels from Bangladesh are not capable to produce entertainment content for refugees according to their entertainment habit. Though only $20 \%$ of respondents admitted that they listen to Myanmar channels, as researchers found, the number may higher than that as most of the male respondents hesitated to admit that they can access FM Channels of Myanmar from Bangladesh. 
Table 2: Radio preference

\begin{tabular}{|l|l|l|}
\hline Radio & Frequency & Per cent \\
\hline Radio Naf & 31 & 62.0 \\
\hline Bangladesh Betar & 6 & 12.0 \\
\hline Myanmar Radio & 10 & 20.0 \\
\hline No preference & 3 & 6.0 \\
\hline Total & 50 & 100.0 \\
\hline
\end{tabular}

Refugees find Radio information authentic:

$78 \%$ of respondents fully and $18 \%$ of respondents partially believe the information they get from Radio. Among them, 24 female respondents, which is $98 \%$ of them, fully believe the information they get from Radio whereas this number is quite lower among male respondents as 15 among 25 of them believe that all the information which produced by radio are true and other 8 respondents partially belief information from radio channels. Access to another medium of information allows male listeners to have different types of information about specific issues. For instance, in the second half of 2019, a rumour spread that a group of people are stealing Rohingya children from camps to devote (killing) them to in the name of God to make the largest bridge of Bangladesh. Government officials working there, with the help of NGOs, used radio channels in order to combat that rumour but failed because this rumour was spread through social media like Facebook and Rohingya people had faith on social media more than Radio. As per the experience of the researcher in this study, Rohingya people believe radio for information regarding health and legal issues but for the religious and socio-cultural matter, they depend mostly on their peer group.

Table 3:- Believing radio information.

\begin{tabular}{|l|l|l|}
\hline Believing radio information & Frequency & Per cent \\
\hline Yes & 39 & 78.0 \\
\hline No & 2 & 4.0 \\
\hline Some of the information & 9 & 18.0 \\
\hline Total & 50 & 100.0 \\
\hline
\end{tabular}

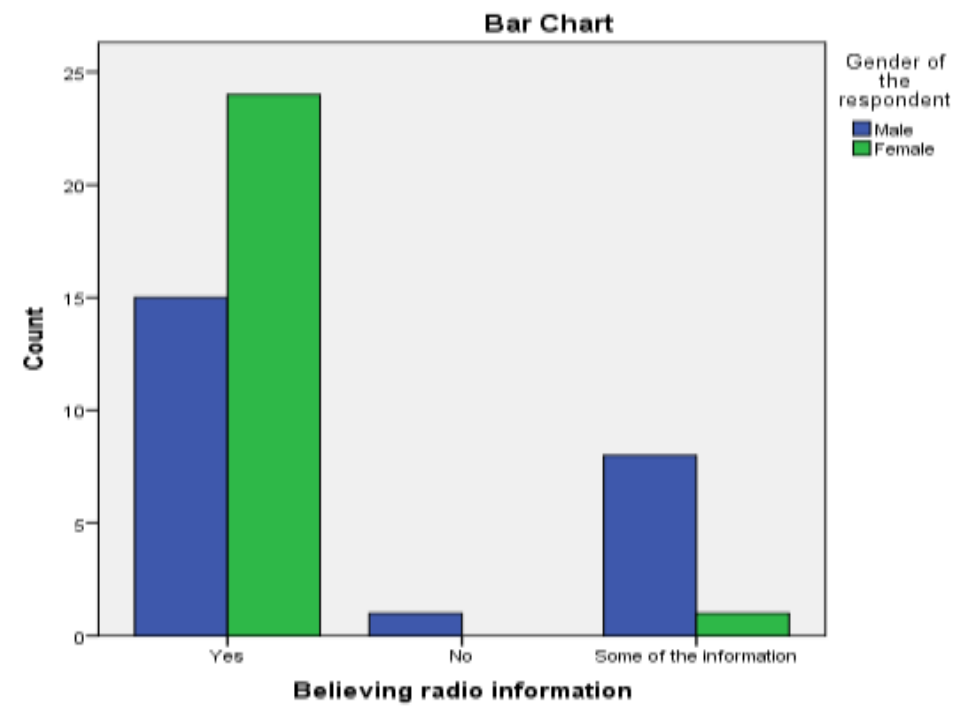

Chart 2:- Believing radio information gender ratio.

Sharing Information from Radio is very common among refugees as they find this information helpful: almost 92 per cent of respondents said that they share the information they get from the radio. As discussed earlier, radio is very popular among refugees for basic information such as places and schedule for food and other aid distribution by humanitarian agencies and male respondents mostly share these types of information with their family members whereas female respondents said that they participate and give feedback to radio talk shows which are about child care and maternity health and they believe sharing this information is very important to save the life 
of newborn children and their mother. 96 per cent of respondents thus believe that Radio program is helpful for their daily activities.

Table 4:- Sharing information with family members.

\begin{tabular}{|l|l|l|}
\hline & Count & Percentage \\
\hline Yes & 46 & 92.0 \\
\hline No & 4 & 8.0 \\
\hline Total & 50 & 100.0 \\
\hline
\end{tabular}

Table 5:- Helpful for daily activities.

\begin{tabular}{|l|l|l|l|l|}
\hline & Frequency & Per cent & Valid Percent & Cumulative Percent \\
\hline Yes & 48 & 96.0 & 96.0 & 96.0 \\
\hline No & 1 & 2.0 & 2.0 & 98.0 \\
\hline Do not Know & 1 & 2.0 & 2.0 & 100.0 \\
\hline Total & 50 & 100.0 & 100.0 & \\
\hline
\end{tabular}

Radio has a positive impact on behavioural or habitual changes among refugees:

Radio influences refugees to adopt new health habits such as washing hands, using safe sanitary kits and so on. Some of the Women respondents also stressed radios importance for letting them know about the legal initiatives by camp authorities against domestic violence they often encounter. They said the audio-dramas about child and women safeties encourage them to go to local authorities if they face such kind of violence. For example, Rohingya people do not have any law about divorce as they follow Islamic rule to do that which sadly often goes against the right of women. Rohingya people are bound to follow the law of Bangladesh while living in the camp and camp officials are trying to reduce the number of cases of marrying more than one at a time by Rohingya men. As per a few female respondents, they came to know about these measures through the radio program and will go camping authorities if such things happen to them.

Table 6:- Contents impact on respondent's behavioural change.

\begin{tabular}{|l|l|l|l|l|}
\hline & Frequency & Per cent & Valid Percent & Cumulative Percent \\
\hline Yes & 42 & 84.0 & 84.0 & 84.0 \\
\hline No & 2 & 4.0 & 4.0 & 88.0 \\
\hline Can't remember & 6 & 12.0 & 12.0 & 100.0 \\
\hline Total & 50 & 100.0 & 100.0 & \\
\hline
\end{tabular}

Camp authorities are failing to use the radio as an effective communication tool:

Radio is found to be effective to spread health and aid-related information inside camps but not proven much effective to distribute information from camp offices which are established in every camp and consist of few government officials and volunteers to monitor and supervise the humanitarian assistance by local and international NGOs. Camp offices are responsible to formulate rules for camps in a different situation and to protect unlawful activities of any types inside the camps. They are also responsible to address the needs of each camp and design the aid work according to that need. For instance, camp in charges and their assistant decides which camp needs more latrine and which camp need more children-friendly places. However, only $20 \%$ of respondents said that they get necessary information related to camps from radio whereas $62 \%$ said did not and $9 \%$ cannot remember getting any information about camp authorities from radio programs.

Table 7:- Information for respondents from camp authority through radio.

\begin{tabular}{|l|l|l|l|l|}
\hline & Frequency & Per cent & Valid Percent & Cumulative Percent \\
\hline Yes & 10 & 20.0 & 20.4 & 20.4 \\
\hline No & 31 & 62.0 & 63.3 & 83.7 \\
\hline Can't remember & 9 & 18.0 & 16.3 & 100.0 \\
\hline Total & 50 & 100.0 & & \\
\hline
\end{tabular}

Refugees prefer channels which give more information regarding their daily life:

Male Rohingya refugees are major concern about the information about outer world especially information which is related to them. Female refugees, on the other hand, are interested in getting information about maternity health and 
health issues regarding children. However, for both group, channels which give information required to them are more preferred. Radio Naf or Bangladesh Beter give information about their daily life in the form of entertainment content and, when asked, female respondents, considered those content as infotainment and define them as Khobor (News). Though $68 \%$ of respondents said that they prefer to listen to channels which produce news content, respondents who listen to contents relevance to their life and who listen channels gives information about their community back in Myanmar, which are respectively $12.8 \%$ and $8.5 \%$, are also preferring channels to listen which give them news or Information. Only 5 among 50 said that they listen to music or other programs of entertainment channels. Sometimes radios situated in Rohingya refugee camps can catch the frequency of FM channels of Rakhine state Myanmar and those channels work as a source of entertainment for many livings in camps.

Table 8:- Reason for channel preference .

\begin{tabular}{|l|l|l|l|}
\hline & Frequency & Valid Percent & Cumulative Percent \\
\hline News content & 32 & 68.1 & 68.1 \\
\hline Entertainment content & 5 & 10.6 & 78.7 \\
\hline The relevance of content with my life & 6 & 12.8 & 91.5 \\
\hline The station's involvement with my community & 4 & 8.5 & 100.0 \\
\hline Total & 47 & 100.0 & \\
\hline
\end{tabular}

Communication through Volunteer is the easiest way of communicating with refugees:

volunteers from local and international NGOs are the primary and most important information source for Rohingya refugees. Maximum of the volunteers working there are local people from Cox's Bazar district and their language is $80 \%$ similar to the language Rohingya refugee speak. So message through volunteers are easily understandable to refugees and thus have the most effective impact on their daily life. More than $65 \%$ of responders, therefore, said that Interpersonal communication through volunteers is the easiest medium to have information. Using sim card, though is illegal inside the refugee camp, most of the male refugees were using Bangladeshi sim card somehow till the end of 2019, and Mobile phone, as responders said, become the second choice for refugees to get important information. Radio, on the other hand, is even least important than Social media as a source of information in Rohingya refugee camps in Bangladesh.

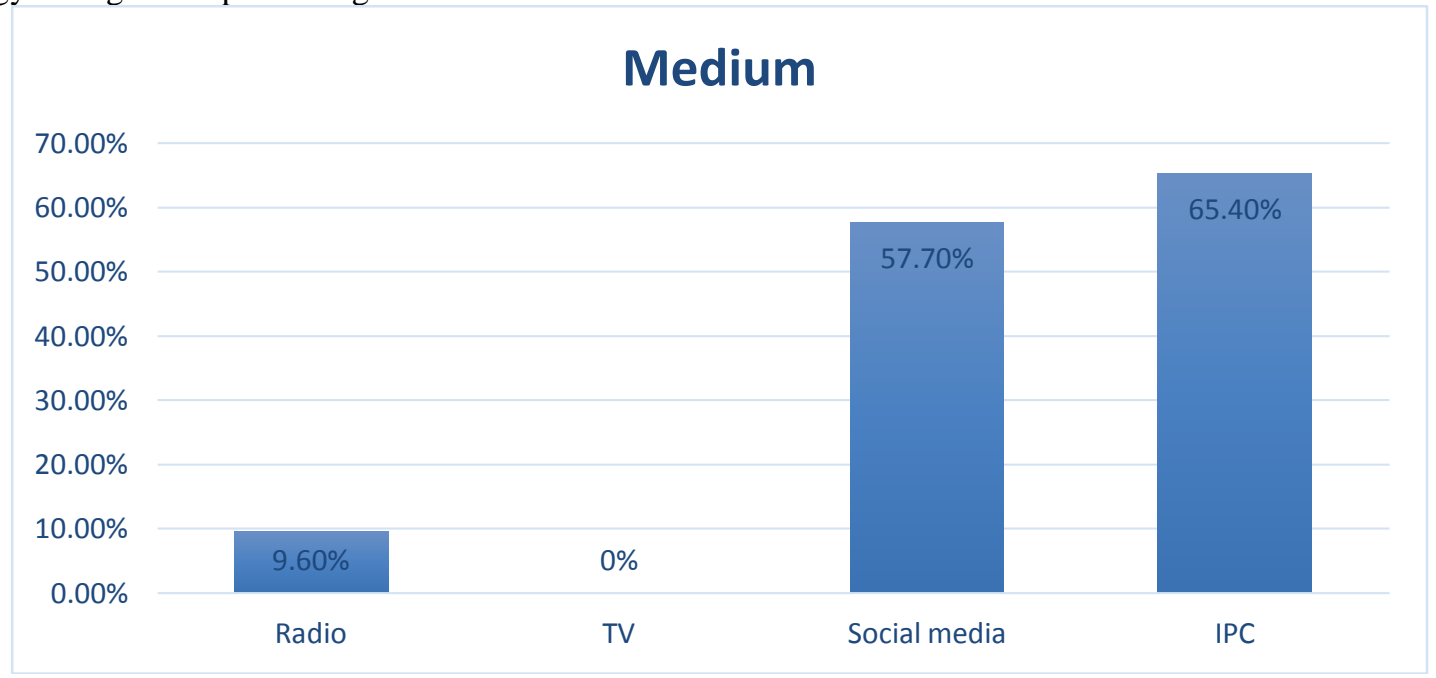

Chart 3:- The easiest medium for sharing information (multiple choice).

Block Heads (Majhis) play the role of the most authentic source of information to Rohingya Refugees:

More than $86 \%$ of respondents put Majhis in the first position while asked to provide three most authentic source of information. More than half of the refugees, after Majhis, believe camp authorities if they find any contradictory information about any specific issue. Neighbours positioned third for the authentic source of news whereas Radio performed the least important role to remove confusion about any information. 


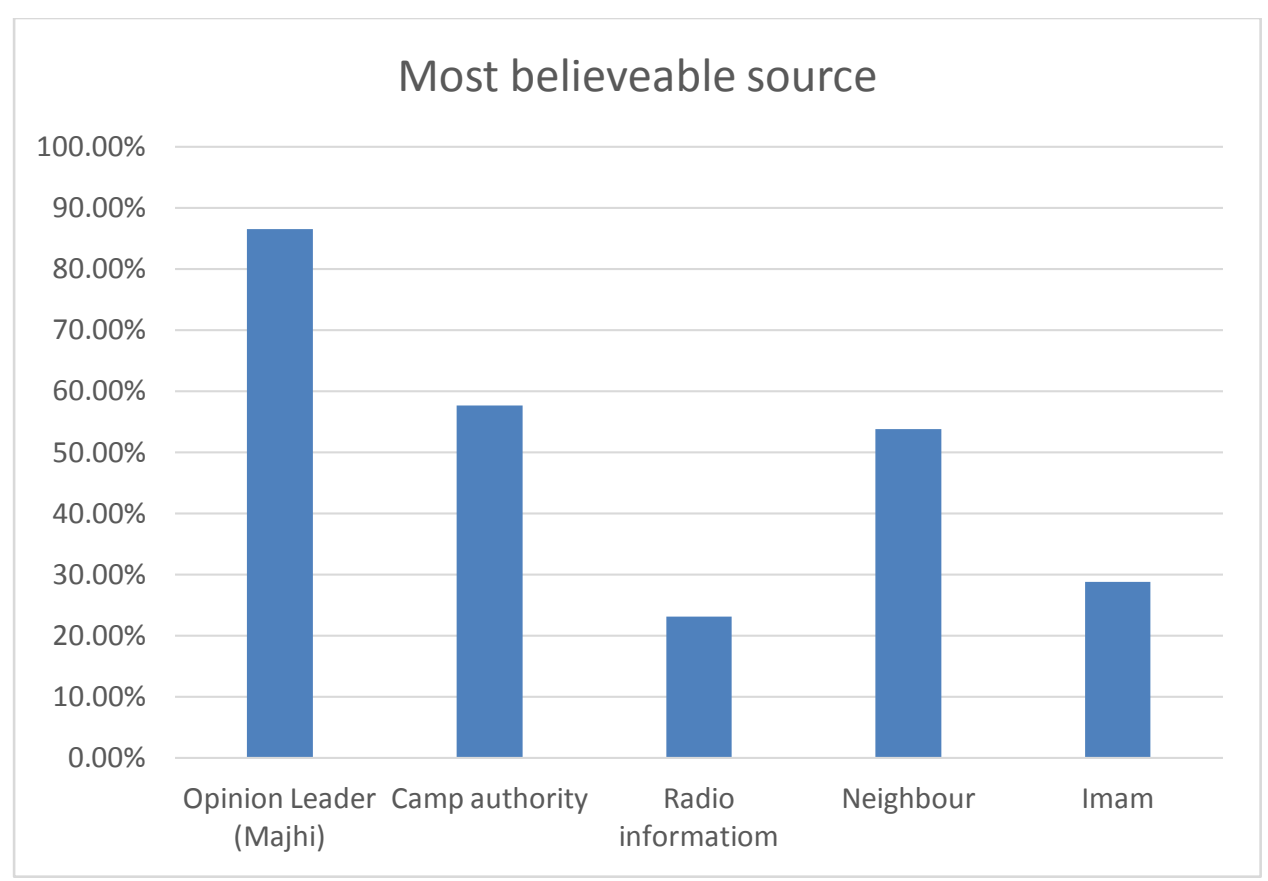

Chart 4:- Most believable source (multiple choice).

\section{Radio is a tool of Humanitarian Communication:}

In Rohingya refugee camps, as the three P criteria by Britanny Card and Ziad Al Achkar(2015), Radio is used to communicate with crisis-affected Population, Rohingya refugee, in this case, to save lives especially it is found to be very effective communication tools for new mothers and children. According to the findings of this study Radio, as a communication tool, surely uphold all the four principles of NGP Code of Conduct. Field level workers from DW or BBC media action collect feedback from Rohingya refugees before they make and disseminate information related content so that they can assist refugees with basic information regarding aid distribution, health etc. which goes with the concept of humanitarian communication by IOM.

\section{Findings From FGD:}

A focus group discussion with Block leaders from Camps (Majhis), Imam (priest from Mosque) and teachers revealed why radio is failing to perform as an effective source of information among Rohingya refugees which are discussed below.

Unavailability of Radio among Majhi (Local Camp leaders): Radios are not available and according to the responses from blockheads, the numbers of radios are very few in camps that it is not possible to spread information through the radio at all. Even camp leaders, known as Majhi by local people and joined the focus group discussion arranged for this study, do not have a radio in their house. They said that sometimes listen to radio news in tea stores. According to them, they depend on educated people to understand all the information on radio news. As per the statement of some religious leaders participated in FDG, they listen to the radio and spread information among refugees about important issues such as legal and health issues during prayer.

An influential portion of camps do not appreciate women having information through Radio: Maximum of Blockheads (Majis) think that radio has no use to women. As women are not educated and not allowed to join or give an opinion in a public gathering, they are not able to share important information they are getting from the radio. Accepting the fact that radio gives health-related information to women who need it most, responders of the FGD argues that women are not able to understand the value of other important information related to local and world politics, thus more men, especially blockheads should be given radios to utilize its power of distributing lifesaving information.

Educated people should have access to Radio: Educated people of refugee camps should have access to radios so that they can understand news from international FM Channels and distribute that information among others, as per 
the discussion among Block Heads, Teachers and Imams through FGD. As the trial about Rohingya refugee massacre begun in The Hague, Netherlands, in 2019, refugees were eager to know the update about that trial and news from BBC and Bangladesh Betar are among few important sources they can get information about the trial. Therefore, FGD responders suggested distributing radios among educated young people so that they can get authentic news from them.

Radio cannot fight rumours inside Rohingya Refugee Camps: Refugee camps are very fertile ground for spreading rumours. According to blockheads and Imams of local mosques, online messenger services speeded the spread of rumours last year. Especially in the case of kidnapping children from the camp, photos and videos from unknown sources had largely created panic inside the camp. While asked, they stated that "100\% of that information they thought were true". Camp in Charges and community radio authorities tried to stop rumours through radio but failed. Some of the blockheads said that volunteers from INGOs like UNHCR made them believe that the pictures and information they are getting through social media are fake. Interpersonal Communication worked better than any other medium of communication while rumours prone to spread, they confirmed.

\section{Though Radio is not a popular medium of information inside Rohingya refugee camps, respondents of FGD emphasized its importance for some cases.}

Weather-related news are most popular for radio listeners: Radio helps them to cope up with the changing weather of southern Bangladesh. Refugee camps are situated in a cyclone-prone humid area and thus information about weather, especially during monsoon time, is very important to refugees and as FDG participants said, radio gives information about where they should go during natural calamities and how can they protect landslides during monsoon time. However, still interpersonal communication through volunteers from different NGOs and alert messages from camp officials through the use of microphone play more effective role spread weather-related news than radio.

News about Myanmar is popular radio content: International news, especially which are related Rohingya refugee issues or present situation of Rakhine state in Myanmar get priorities among other news from Radio news program. As per the FDG respondents camp leaders, school teachers and religious leaders listen to international radio channel such as BBC to learn about what global bodies of powerful countries are doing to solve the crises regarding Rohingya refugees. They also listen to Bangladesh Betar to know about the present situation of Bangladesh.

\section{Conclusion:-}

For the hundreds of thousands of Rohingya refugees living in refugee settlements in Bangladesh, having information is also an important thing, as everyone doesn't have access to information. This study finds that opinion leaders such as Majhi, Imam and senior citizen played an important role to spread information among the mass Rohingya population. Even most of the Rohingya refugee believes that every Majhi should have a radio to disseminate information among the mass audiences. This study also finds out that community radio is more effective in refugee camp rather than national radio and most of the refuge believe in radio information and they share radio information with another community member. This study also finds out that, radio has an impact on behavioural change of Rohingya people and camp authority also use radio as a communication tool. Under humanitarian communication theoretical approach, this study tries to establish a link between radio and Rohingya Populations, their humanitarian principles and purposes of access to information. This study finds that Radio, as a communication tool, covers beneficiary communication such as providing weather forecast and other necessary news for the community In the Rohingya refugee camps in Bangladesh. The findings also indicate that radio plays an active role in communication for development (C4D) because it helps Rohingya people in a positive way to change their behaviour. The study finds that that language or medium of communication was the biggest challenge for this research and surveying a refugee camp will set trauma in your mind which may set obstacles for you to live a normal life for few days. This research paper will help the future researcher to understand the strength and weakness of radio as a communication medium in a refugee camp and it will inspire development organizations who are working in Rohingya Refugee Camp to reevaluate their strategy in terms of communication for development.

\section{Bibliography:-}

1. Backhaus, Bridget. 2019. "Community Radio as Amplification of Rural Knowledge Sharing." Asia Pacific Media Educator 29(2):137-50. 
2. Butler, Natacha. 2018. "Radio for Refugees: Show Provides Information on Asylum." Aljazeera. Retrieved June 29, $2020 \quad$ (https://www.aljazeera.com/news/2018/08/radio-refugees-show-information-asylum180814183704973.html).

3. Hansen, Anders, and David Machin. 2018. Media and Communication Research Methods. Macmillan International Higher Education.

4. Hansard, Zeenat. 2018. "International Media - Community Radio Serves Rohingya Refugees in Cox's Bazaar." RFI. Retrieved June 29, 2020 (http://www.rfi.fr/en/asia-pacific/20181014-community-radio-serves-rohingyarefugees-cox-bazaar).

5. Hugelius, Karin, Mike Adams, and Eila Romo-Murphy. 2019. "The Power of Radio to Promote Health and Resilience in Natural Disasters: A Review." International Journal of Environmental Research and Public Health 16(14).

6. Jasmin, Rietdorf, and Marshall Andrea. 2020. "Reporting the Coronavirus at a Rohingya Camp: 'Saving Lives Is Now the Most Important Task' | DW | 08.04.2020." DW.COM. Retrieved June 29, 2020 (https://www.dw.com/en/reporting-the-coronavirus-at-a-rohingya-camp-saving-lives-is-now-the-mostimportant-task/a-53061759).

7. Kristina, Jovanovski, and Polykastro. 2016. "Radio Station Seeks to Give Refugees Information and a Voice DW | 13.06.2016.” DW.COM. Retrieved June 29, 2020 (https://www.dw.com/en/radio-station-seeks-to-giverefugees-information-and-a-voice/a-19326634).

8. Macaulay, Larry. 2016. "Refugee Radio Network: Giving Refugees a Voice - Prix Italia News -." PRIX Italia. Retrieved June 29, 2020 (http://www.rai.it/dl/siti/html/Refugee-Radio-Network-Giving-Refugees-a-Voice67dce23f-005a-48dc-8f63-7679284d4571.html).

9. Mesmar, Sandra, Reem Talhouk, Chaza Akik, Patrick Olivier, Imad H. Elhajj, Shady Elbassuoni, Sarah Armoush, Joumana Kalot, Madeline Balaam, and Aline Germani. 2016. "The Impact of Digital Technology on Health of Populations Affected by Humanitarian Crises: Recent Innovations and Current Gaps." Journal of Public Health Policy 37(2):167-200.

10. O. Nyumba, Tobias, Kerrie Wilson, Christina J. Derrick, and Nibedita Mukherjee. 2018. "The Use of Focus Group Discussion Methodology: Insights from Two Decades of Application in Conservation." Methods in Ecology and Evolution 9(1):20-32.

11. OCHA. 2017. "Rohingya Refugee Crisis." OCHA. Retrieved June 30, 2020 (https://www.unocha.org/rohingyarefugee-crisis).

12. Raymond, N. A., Britney Card, and Ziad al Achkar. 2015. "What Is 'Humanitarian Communication'? Towards Standard Definitions and Protections for the Humanitarian Use of ICTs." in European Interagency Security Forum (EISF).

13. UNHCR. 2020a. "Broadcasting Hope on World Radio Day." UNHCR. Retrieved June 29, 2020 (https://www.unrefugees.org.au/about-us/news/world-radio-day/).

14. UNHCR. 2020b. "Situation Refugee Response in Bangladesh." Retrieved June 30, 2020 (https://data2.unhcr.org/en/situations/myanmar_refugees).

15. Wilson, Fredrick, Melea Jude Moses, and Justin Wilson. 2019. "Principles and Practice of Humanitarian Communication during and After Natural Disasters and Armed Conflicts." Journal of Analog and Digital Communications 4(3). 